\title{
Inhibitory effect of losartan, an AT1 angiotensin II receptor antagonist, on increased leucocyte entrapment in retinal microcirculation of diabetic rats
}

\author{
F Mori, T Hikichi, T Nagaoka, J Takahashi, N Kitaya, A Yoshida
}

Br J Ophthalmol 2002;86:1 172-1174

See end of article for authors' affiliations

\section{Correspondence to:} Fumihiko Mori, MD, PhD Department of Ophthalmology,

Asahikawa Medical College, Midorigaoka Higashi 2-1-1-1

Asahikawa 078-8510

Japan;

morinao@d5.dion.ne.jp

Accepted for publication 29 April 2002

\begin{abstract}
Background: The effectiveness of losartan for the treatment of leucocyte entrapment in the retinal microcirculation of diabetic rats was evaluated quantitatively.

Methods: After diabetes was induced by injection of streptozotocin (STZ), the rats were divided into two subgroups. The first subgroup $(n=6)$, received no medications; the second subgroup $(n=6)$ was given fresh drinking water supplemented with losartan $(5 \mathrm{mg} / \mathrm{kg} /$ day) for 4 weeks. Six rats that were not injected with STZ or given medications served as controls. 4 weeks after intervention, leucocyte dynamics in the retina were observed using acridine orange digital fluorography. Leucocyte entrapment in the retina was compared among the three groups.

Results: In the untreated diabetic rats, the number of trapped leucocytes (6.1 (SD 1.4) cells $/ \mathrm{mm}^{2}$ ) increased significantly compared with control rats $\left(2.8(1.2)\right.$ cells $\left./ \mathrm{mm}^{2} ; \mathrm{p}=0.005\right)$ and diabetic rats treated with losartan (3.1 (0.9) cells $\left./ \mathrm{mm}^{2} ; p=0.0002\right)$.

Conclusions: Losartan, an ATl angiotensin II receptor antagonist, inhibited increased leucocyte entrapment in the diabetic retina. The authors demonstrated that losartan may have therapeutic efficacy in preventing development of diabetic retinopathy. Further clinical studies of the effect of the angiotensin receptor antagonist on preventing development of diabetic retinopathy are needed.
\end{abstract}

\section{METHODS}

\section{Animals}

Eighteen Brown-Norway male rats (weight approximately 250 g) were treated according to the Association for Research in Vision and Ophthalmology statement on the use of animals in vision and ophthalmic research. The rats were anaesthetised for all procedures. Hyperglycaemia was induced with one intraperitoneal injection of streptozocin (STZ) $(60 \mathrm{mg} / \mathrm{kg}$, Sigma Chemical Co, St Louis, MO, USA) in citrate buffered saline ( $\mathrm{pH} 4.5$ ) after an overnight fast. The plasma glucose concentration was measured 48 hours after the STZ injection. The animals were determined to be diabetic if their non-fasting plasma glucose concentrations were greater than $250 \mathrm{mg} / \mathrm{dl}$. Non-fasting blood glucose concentration, body weight, and water intake were monitored weekly.

After the animals developed diabetes, they were divided into two subgroups. The first subgroup $(\mathrm{n}=6)$ was left untreated; the second subgroup $(n=6)$ was given fresh drinking water supplemented with losartan potassium (Mikromol GmbH, Luckenwalde, Germany; concentration 50 $\mathrm{mg} / \mathrm{l})$. The rats ingested approximately $5 \mathrm{mg} / \mathrm{kg} / \mathrm{day}$ of losartan for 4 weeks. The rats that were not injected with STZ or medications served as controls $(n=6)$.

\section{Acridine orange digital fluorography}

The leucocyte dynamics in the retina were observed by acridine orange digital fluorography using the modified methods of Nishiwaki et al. ${ }^{13}{ }^{14}$ Leucocytes were labelled with a fluorescent nuclear dye of acridine orange (Wako Pure Chemical, Osaka, Japan) administered intravenously and then imaged with a confocal scanning laser ophthalmoscope (SLO) (Heidelberg Retinal Angiograph, Heidelberg Engineering, Carlsbad, CA, USA). The argon blue laser was the illumination source. A regular emission filter for fluorescein angiography was used, because the spectral properties of leucocytes stained with acridine orange are similar to those of sodium fluorescein.

Four weeks after intervention, the animals were anaesthetised with intramuscular ketamine hydrochloride and intraperitoneal pentobarbitone sodium, and the pupils were dilated. Each rat had a catheter placed into the right jugular vein. Acridine orange was dissolved in sterile saline at a concentration of $1.0 \mathrm{mg} / \mathrm{ml}$, and the solution was injected through 
Table 1 Animal characteristics

\begin{tabular}{llll}
\hline & $\begin{array}{l}\text { Untreated diabetic } \\
\text { rats }(n=6)\end{array}$ & Control rats $(n=6)$ & $\begin{array}{l}\text { Diabetic rats treated } \\
\text { with losartan }(n=6)\end{array}$ \\
\hline $\begin{array}{l}\text { Body weight }(\mathrm{g}) \\
\text { Blood glucose }(\mathrm{mg} / \mathrm{dl})\end{array}$ & $242.5(16.0)^{*}$ & $303.3(16.3)$ & $230.0(34.6)^{*}$ \\
\hline${ }^{*} \mathrm{p}<0.05$ compared with control rats. & $390.3(65.4)^{*}$ & $85.5(6.2)$ & $363.5(63.8)^{*}$ \\
\hline
\end{tabular}

the right jugular vein catheter at a rate of $1 \mathrm{ml} / \mathrm{min}$. The fundus of the left eye was observed by SLO in the $10^{\circ}$ field. Thirty minutes after injection, the fundus was observed to evaluate leucocyte entrapment in the retina. The digital images were saved on a hard drive in a confocal SLO. An observation area surrounding the optic disc was determined by drawing a polygon surrounded by the adjacent major retinal vessels. The area was measured in pixels on a monitor in a confocal SLO, and the density of trapped leucocytes was calculated by dividing the number of trapped leucocytes, seen as fluorescent dots, by the area of the observation region. The densities of the leucocytes were calculated generally in eight peripapillary observation areas. An average density of trapped leucocytes for each rat was obtained by averaging the eight density values. The numbers of trapped leucocytes were calculated by a masked observer. After the experiment, the rats were killed with an overdose of anaesthesia, and the eyes were enucleated to determine a calibration factor for converting values measured on a monitor (in pixels) in a confocal SLO into real values (in $\mu \mathrm{m})$. The calibration factor is the ratio between the actual size of each optic disc measured by microscopy and the apparent value on a computer monitor in a confocal SLO. All data were converted into real values using the calibration factor.

\section{Statistical analysis}

All comparisons were performed using Fisher's PLSD after one way analysis of variance. All results are expressed as mean (SD). A p value of 0.05 was considered statistically significant.

\section{RESULTS}

Table 1 shows the body weights and blood glucose levels after 4 weeks of intervention in the three groups. Digitised images of the fundus obtained from an untreated diabetic rat (A), a control rat (B), and a diabetic rat treated with losartan (C) 30 minutes after dye administration are shown in Figure 1.

Figure 2 shows the number of leucocytes trapped in the retinal microcirculation in the three groups. In the untreated diabetic rats, the number of trapped leucocytes (6.1 (1.4) cells $\left./ \mathrm{mm}^{2}\right)$ increased significantly compared to the control rats (2.8 (1.2) cells $\left./ \mathrm{mm}^{2} ; \mathrm{p}=0.005\right)$ and the diabetic rats treated with losartan (3.1 (0.9) cells $\left./ \mathrm{mm}^{2} ; \mathrm{p}=0.0002\right)$.

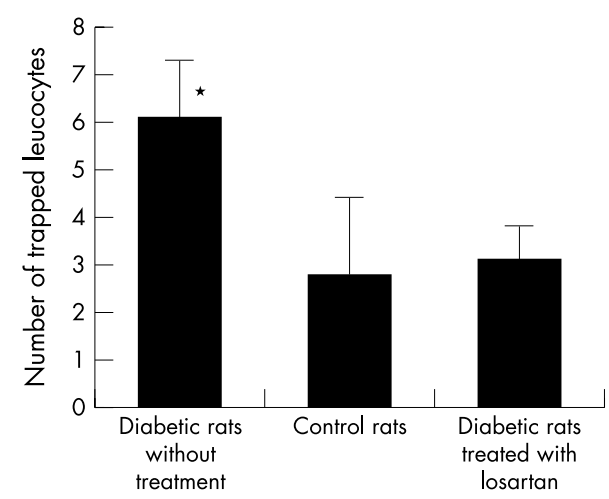

Figure 2 Leucocytes trapped in the retinal microcirculation. Values are means $(S D)$. ${ }^{*} p<0.05$ compared with control rats and diabetic rats treated with losartan.

\section{DISCUSSION}

In the present study, we demonstrated the inhibitory effects of losartan, an ATl angiotensin II receptor antagonist, on leucocyte entrapment in the diabetic retina. Miyamoto et al reported that leucocyte entrapment increased in the diabetic retina and VEGF induces retinal leucocyte entrapment, in part, through intercellular adhesion molecule- $1 .{ }^{415}$ Otani et al reported that AT II induced VEGF mRNA expression in retinal vascular pericytes under high glucose conditions and induced mRNA expression of kinase insert domain protein receptor, a VEGF receptor, in retinal vascular endothelial cells through the ATl receptor. ${ }^{78}$ ATl angiotensin II receptor antagonist may inhibit increased leucocyte entrapment in the diabetic retina mediated by RAS-VEGF interaction. Further mechanistic studies about this effect are needed.

Losartan normalised increased leucocyte entrapment in the diabetic retina. However, there were no differences in blood glucose levels between the treated and untreated diabetic groups. A few studies have reported a protective effect of losartan on a model of retinal angiogenesis. ${ }^{16}{ }^{17}$ We also reported that losartan inhibited development of laser induced choroidal neovascularisation in rats. ${ }^{18}$ Losartan seemed to inhibit not only retinal and choroidal angiogenesis but also leucocyte
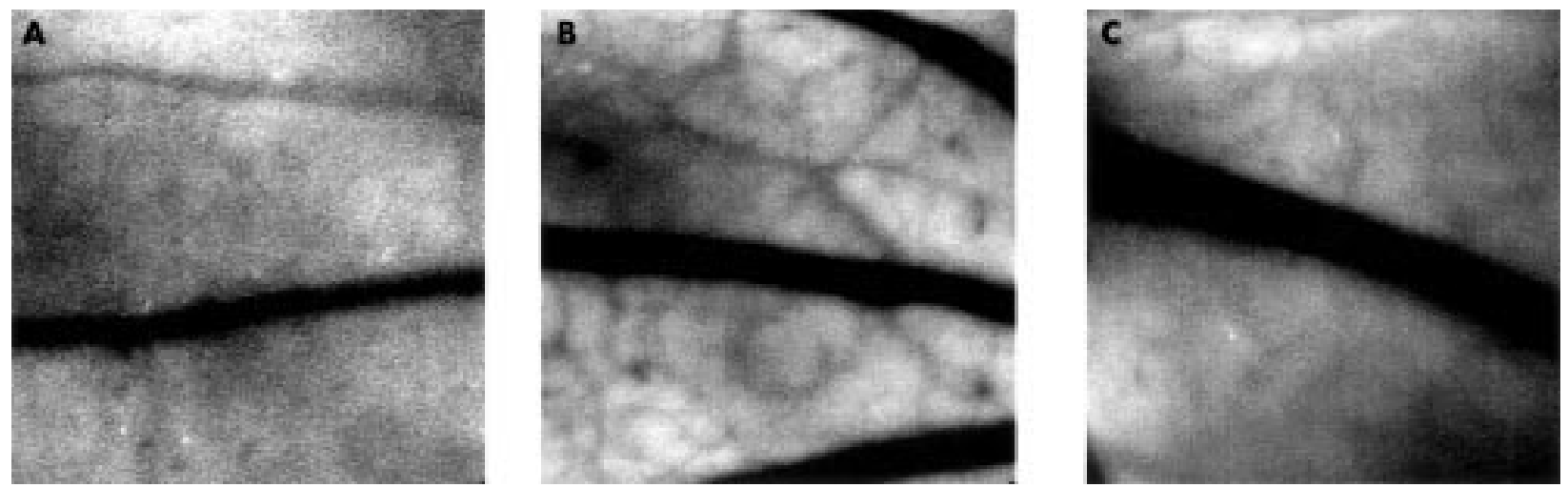

Figure 1 Leucocytes trapped in the retinal microcirculation were observed as fluorescent dots 30 minutes after acridine orange injection in an untreated diabetic rat (A), a control rat (B), and a diabetic rat treated with losartan (C). 
entrapment in the diabetic retina mediated by RAS independent of blood glucose.

Several investigators reported that losartan is a valuable new drug in the clinical treatment of another diabetic complication, diabetic nephropathy. ${ }^{10-12}$ Several investigators reported that increased leucocyte entrapment in the retina with early stage diabetes may be associated with vascular non-perfusion and vascular leakage and may initiate a series of events leading to diabetic retinopathy. ${ }^{3-5}$ Angiotensin converting enzyme inhibitor was associated with reduced proliferative diabetic retinopathy, providing a potential clinical role for suppression of RAS in preventing and treating retinal neovascularisation. ${ }^{9}$ ATl angiotensin II receptor antagonist may be a valuable new drug in the clinical treatment of not only diabetic nephropathy but also retinopathy.

In the present study, we demonstrated that losartan may have therapeutic efficacy in preventing the development of diabetic retinopathy. To our knowledge, there have been no reports that ATl angiotensin II receptor antagonist has therapeutic efficacy in preventing the development of diabetic retinopathy clinically. Further clinical studies of the effect of the angiotensin receptor antagonist on preventing the development of diabetic retinopathy are needed.

\section{ACKNOWLEDGEMENTS}

This study was supported by grant in aid for encouragement of young scientists 13771007 (FM) and scientific research (C) 14571652(AY).

\section{Authors' affiliations}

F Mori, T Hikichi, T Nagaoka, J Takahashi, N Kitaya, A Yoshida Department of Ophthalmology, Asahikawa Medical College, Asahikawa, Japan

The authors have no proprietary interest in any aspect of this technology.

\section{REFERENCES}

1 Zatz R, Brenner BM. Pathogenesis of diabetic microangiopathy. The hemodynamics view. Am J Med 1986:80:443-5.

2 Schroder S, Palinski W, Schmid-Schonbein GW. Activated monocytes and granulocytes, capillary nonperfusion, and neovascularization in diabetic retinopathy. Am J Pathol 1991;139:81-100.
3 Miyamoto K, Hiroshiba N, Tsujikawa A, et al. In vivo demonstration of increased leukocyte entrapment in retinal microcirculation of diabetic rats. Invest Ophthalmol Vis Sci 1998;39:2190-4.

4 Miyamoto K, Khosrof S, Bursell SE, et al. Prevention of leukostasis and vascular leakage in streptozotocin-induced diabetic retinopathy via intercellular adhesion molecules-1 inhibition. Proc Natl Acad Sci USA 1999;96:10836-41.

5 Nonaka A, Kiryu J, Tsujikawa A, et al. PKC- $\beta$ inhibitor (LY333531) attenuates leukocyte entrapment in retinal microcirculation of diabetic rats. Invest Ophthalmol Vis Sci 2000;41:2702-6.

6 Aiello LP, Avery RL, Arrigg PG, et al. Vascular endothelial growth factor in ocular fluid of patients with diabetic retinopathy and other retinal disorders. N Engl J Med 1994;331:1480-7.

7 Otani A, Takagi H, Suzuma K, et al. Angiotensin II potentiates vascular endothelial growth factor-induced angiogenic activity in retinal microcapillary endothelial cells. Circ Res 1998;82:619-28.

8 Otani A, Takagi $\mathrm{H}, \mathrm{Oh} \mathrm{H}$, et al. Angiotensin II potentiates vascular endothelial growth factor expression in bovine retinal pericytes. Invest Ophthalmol Vis Sci 2000;41:1192-9.

9 Chaturvedi N, Sjolie AK, Stephenson JM, et al. Effect of lisinopril on progression of retinopathy in normotensive people with type 1 diabetes. Lancet 1998;351:28-31.

10 Andersen S, Tarnow L, Rossing P, et al. Renoprotective effects of angiotensin II receptor blockade in type 1 diabetic patients with diabetic nephropathy. Kidney Int 2000;57:601-6.

11 Lacourciere Y, Belanger A, Godin C, et al. Long-term comparison of losartan and enalapril on kidney function in hypertensive type 2 diabetics with early nephropathy. Kidney Int 2000;58:762-9.

12 Brenner BM, Cooper ME, Zeenw DD, et al. Effect of losartan on renal and cardiovascular outcomes in patients with type 2 diabetes and nephropathy. N Engl J Med 2001;345:861-9.

13 Nishiwaki H, Ogura Y, Kimura H, et al. Quantitative evaluation of leukocyte dynamics in retinal microcirculation. Invest Ophthalmol Vis Sci 1995;36:123-30.

14 Nishiwaki $\mathbf{H}$, Ogura $Y$, Kimura $H$, et al. Visualization and quantitative analysis of leukocyte dynamics in retinal microcirculation of rats. Invest Ophthalmol Vis Sci 1996;37:1341-7.

15 Miyamoto K, Khosrof S, Bursell S-E, et al. Vascular endothelial growth factor (VEGF)-induced retinal vascular permeability is mediated by intercellular adhesion molecule-1 (ICAM-1). Am J Pathol 2000; 156:1733-9.

16 Lonchampt M, Pennel L, Duhault J. Hyperoxia/normoxia-driven retinal angiogenesis in mice: a role for angiotensin II. Invest Ophthalmol Vis Sci 2001;42:429-32.

17 Moravski CJ, Kelly DJ, Cooper ME, et al. Retinal neovascularization is prevented by blockade of the renin-angiotensin system. Hypertension 2000;36: 1099-104

18 Hikichi T, Mori F, Takamiya A, et al. Inhibitory effect of losartan on laser-induced choroidal neovascularization in rats. Am J Ophthalmol $2001 ; 132: 587-9$. 